\title{
Experience Finding MS Project Alternatives at CERN
}

\author{
Maria Alandes Pradillo ${ }^{1}$, Pete Jones ${ }^{1}$, and Piotr Jan Seweryn ${ }^{1, *}$ \\ ${ }^{1}$ European Organization for Nuclear Research (CERN)
}

\begin{abstract}
As of March 2019, CERN is no longer eligible for academic licences of Microsoft products. For this reason, CERN IT started a series of task forces to respond to the evolving requirements of the user community with the goal of reducing as much as possible the need for Microsoft licensed software. This exercise was an opportunity to understand better the user requirements for different types of applications. Here we focus on MS Project, the dominant PCbased project management software, which has been used at CERN for many years. There were over 1,500 installations at CERN when the task force started, with a heterogeneous pool of users in terms of required functionality, area of work and expertise. This paper will present an evaluation of users' needs and whether they could be fulfilled with cheaper and less advanced solutions for project management and scheduling. Moreover, selected alternatives, their deployment and lessons learned will be described in more detail. Finally, it will present the approach on how to communicate, train and migrate users to the proposed solutions.
\end{abstract}

\section{Introduction}

As of March 2019, CERN is no longer eligible for academic licences of Microsoft products. Since 2018, CERN's Information Technology Department has started a set of internal task forces, the so called MALT project, to understand better what other alternatives are available on the market for all the existing Microsoft applications used at CERN. The change of licence model has presented an opportunity to review the existing policies and recommendations for many applications. Microsoft applications have been openly available to CERN users for the past years without any restrictions. Since then, many interesting alternatives have become popular in Industry and Academia. For example, collaborative models relying on web based applications are now a common trend. The MALT project aims at identifying CERN use cases, while exploring new ways of working, avoiding vendor lock-in, decreasing risk and dependency and keeping hands on the data to serve all the relevant use cases. In this paper, we will focus on the activity that studied and proposed possible alternatives for MS Project.

Section 2 presents the status of planning and scheduling tools at CERN. Section 3 describes the market survey carried out to identify alternatives for MS Project and the process to select candidate tools and how they were evaluated. Section 4 gives more details on the selected alternative applications. Section 5 focuses on the interaction with the user community in terms of communication, training and migration strategies. Finally, section 6 summarises the conclusions and lessons learnt from this exercise.

\footnotetext{
*e-mail: maria.alandes.pradillo@cern.ch
} 


\section{Planning and Scheduling tools at CERN}

In April 2018, a survey was launched within CERN to understand the use of planning and scheduling tools in the organisation. At that time, more than 1,500 users had MS Project installed in their PCs, although less than 800 were actively using it. The survey was sent to the 1,500 users of MS Project and also to user communities of similar applications that were identified (e.g. Merlin users on the macOS platform) 240 users replied to the survey. As Figure 1 shows, MS Project was the most popular planning and scheduling tool.

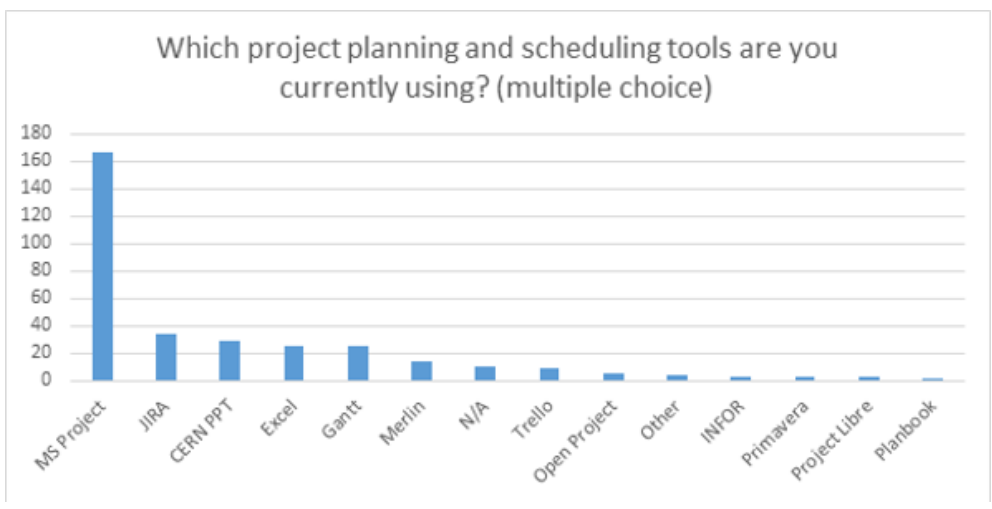

Figure 1. MS Project Survey - Planning and Scheduling Ecosystem at CERN

As shown in 2, most of the users who replied to the survey had critical dependencies on planning and scheduling tools to carry out their tasks. These were mostly average users (those making use of "Mandatory features", as shown in Figure 4) with a second major community of advanced users (those making use of "Advanced features", also shown in Figure 4). Those users who depend on MS Project to do the required job were more likely to participate in the survey and share their feedback.

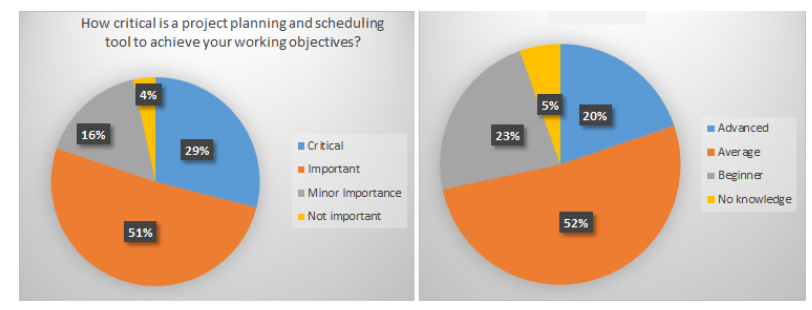

Figure 2. MS Project Survey - Importance of planning and scheduling tools and user expertise

There were three large communities of users actually relying on MS Project: the team managing the schedules to work on the CERN accelerator complex [1] (around 200 users), the team managing the upgrade works in the ATLAS experiment [2] (around 180 users) and the team working on the Site Management and Building department [3] (around 50 users). The two bigger communities were happy to explore other alternatives for MS Project as a long term strategy, but due to timing constraints, they needed to continue using MS Project for a few more years. Other smaller communities were in fact able to consider using the proposed alternatives and stop using MS Project completely by the time we change contract 


\section{CHEP 2019}

in March 2019. At the same time, there are still some teams who have decided to continue working with MS Project, as they have considered it the tool that best fits their needs.

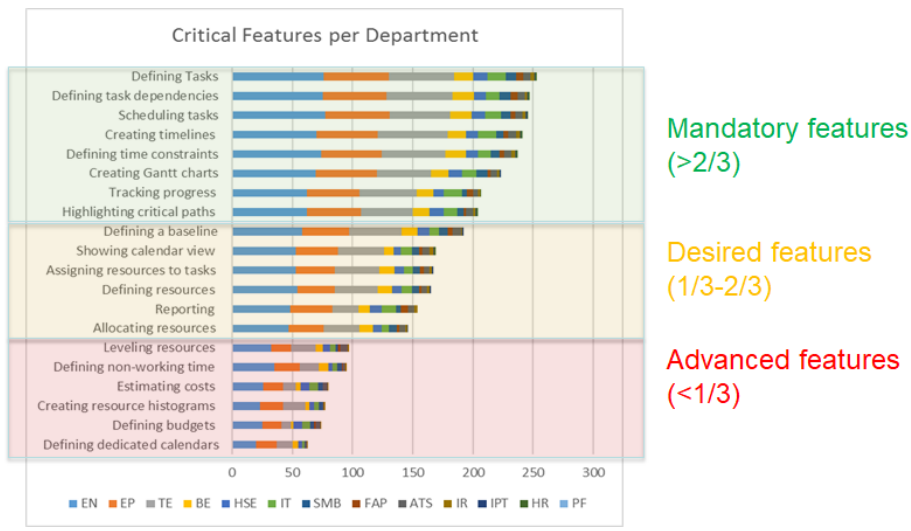

Figure 3. MS Project Survey - Features per Department

Figure 3 shows the study carried out to understand which planning and scheduling features were needed by most users at CERN. 2/3 of the users needed the features described as mandatory. This means that any alternative tool should provide at least those features to satisfy most of the users' needs. $1 / 3$ of the users would be considered as advanced users, which means they required some advanced features, which may eventually justify to continue using MS Project.

\section{Market analysis}

In parallel to understanding CERN use cases for planning and scheduling tools, a detailed market analysis was performed. In the end JIRA Gantt Chart Plugin and DHTMLX Gantt were selected as alternatives for MS Project. The process to come up with these two applications is explained below.

Several proprietary and open source tools were identified. One of the requirements for an alternative tool was to provide multi-platform support. Figure 4 shows how planning and scheduling features were evaluated for each tool on Linux, Mac and Windows platforms.

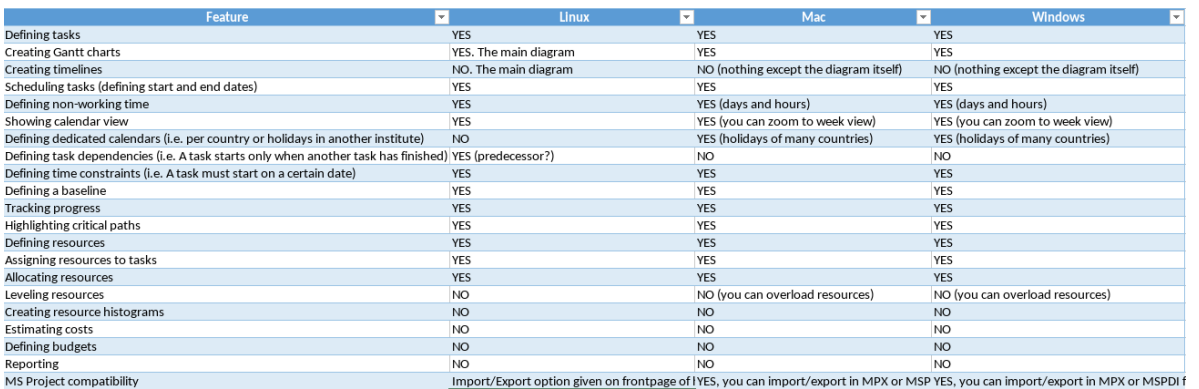

Figure 4. Market Analysis - Example of feature analysis

The evaluated tools were: 
- OpenProject: https://cern.ch/openproject

- Project Libre: https://www.projectlibre.com/

- Gantt Project: http://www.ganttproject.biz/

- GeniusProject: https://www.geniusproject.com/

- Task Juggler: http://taskjuggler.org/

- RationalK PM: https://rationalk.ch/pm

- Jira: https://www.atlassian.com/software/jira

- DHTMLX Gantt: https://dhtmlx.com/

Figure 5 shows one of the summary tables used during the assessment of the tools. Several iterations were needed to come up with a shortlist. Features like open source or web based deployment were also important criteria for the final candidate list.

\begin{tabular}{|l|l|l|l|l|}
\hline & $\begin{array}{l}\text { Mandatory } \\
\text { Features }\end{array}$ & Advantages & Disadvantages & Shortlisted \\
\hline $\begin{array}{l}\text { Open } \\
\text { Project }\end{array}$ & NO & $\begin{array}{l}\text { Open Source } \\
\text { Nice and simple GU }\end{array}$ & $\begin{array}{l}\text { Needs a plugin in MS Project to export } \\
\text { files. This plugin is not available in MS } \\
\text { Project 2016 } \\
\text { No offline capability }\end{array}$ & $\checkmark$ \\
\hline $\begin{array}{l}\text { Project } \\
\text { Libre }\end{array}$ & YES & Open Source & None detected so far & $\checkmark$ \\
\hline $\begin{array}{l}\text { Gantt } \\
\text { Project }\end{array}$ & YES(*) & Open Source & $\begin{array}{l}\text { Requires Java 8 which will be soon EOL } \\
\text { but it works also with Java 9 and 10 }\end{array}$ & $\checkmark$ \\
\hline $\begin{array}{l}\text { Genius } \\
\text { Project }\end{array}$ & YES(*) & None & $\begin{array}{l}\text { Bad usability } \\
\text { Proprietary }\end{array}$ & X \\
\hline $\begin{array}{l}\text { Task } \\
\text { Juggler }\end{array}$ & YES & Open Source & $\begin{array}{l}\text { Input through JSON, No GUI } \\
\text { Development stopped }\end{array}$ & $\mathrm{X}$ \\
\hline
\end{tabular}

Figure 5. Market Analysis - Assessment Table during one of the iterations

In the end JIRA Gantt Chart Plugin and DHTMLX Gantt were selected as alternatives for MS Project. These two tools are presented in more detail in the sections that follow. Other tools like Project Libre, Gantt Project and Open Project were seriously considered. The disadvantages with these tools are summarised in Figure 6:

- Web based deployment was an important criteria. Due to the international nature of CERN, it's very common for teams to be split in different locations. Moreover, most projects at CERN require collaboration and sharing of tasks. Open source tools like ProjectLibre and Gantt Project could not be considered for wider deployment as they are desktop based applications. However, these tools are recommended to users who manage individual plans and schedules, as they are suitable alternatives for basic planning and scheduling.

- Import of MS Project files. This was a "must have" criteria. Many users have legacy MS Project files and it was necessary to be able to import them into any proposed alternative. For this reason, applications like Open Project could not be considered.

\section{Deployed alternatives}

\subsection{JIRA Gantt Chart plugin}

JIRA by Atlassian [5] is a well known bug tracking, issue tracking and project management tool and has been supported by the CERN IT Department for many years [6]. There are 100s 


\begin{tabular}{|c|c|c|c|c|c|c|c|}
\hline Tool & Multiplatform & $\begin{array}{c}\text { Web } \\
\text { based }\end{array}$ & $\begin{array}{l}\text { Import/Export } \\
\text { MS Project } \\
\text { Files }\end{array}$ & Tasks & Resources & Costs & Functionality \\
\hline Projectlibre & $r$ & $x$ & $\checkmark$ & $r$ & $r$ & $r$ & $\bullet \bullet$ \\
\hline Gantt Project & $\checkmark$ & $x$ & $x$ & $r$ & $r$ & $x$ & $\diamond$ \\
\hline Open Project & $\checkmark$ & $r$ & $x$ & $r$ & $x$ & $r$ & $\diamond \bullet$ \\
\hline
\end{tabular}

Figure 6. Market Analysis - Assessment Table for three of the shortlisted applications

of projects at CERN that are already relying on JIRA to track project tasks. The tool is available through the web browser. Issues are the main building blocks of a project and within a JIRA project, issues can be created, shared and tracked. JIRA supports add-ons including third party ones. At the time of evaluating alternatives for MS Project, the CERN JIRA instance was already offering a third party tool for gantt charts [10]. However, this tool was very limited and there were very few users relying on it. After evaluating several other plugins for gantt charts, WBS Gantt Chart for JIRA offered by ricksoft-inc.com was selected. The Gantt chart options are available from the JIRA top menu and includes an issue detail view and critical path view. It allows for import to and export from MS Project and also has a feature for a one-click export to MS Excel. Even though JIRA is a proprietary and commercial application, as is the WBS Gantt-Chart plugin, it is possible with WBS Gantt to export files in XML format. This format can be then manipulated with existing libraries like MPXJ [11] and therefore it is feasible to import projects to other applications, thus mitigating the risk for vendor lock-in. The long term operations and maintenance of WBS Gantt-Chart plugin is almost negligible, as it is integrated in the already existing operations and maintenance of JIRA and represents a very small amount of work (basically upgrades of the software).

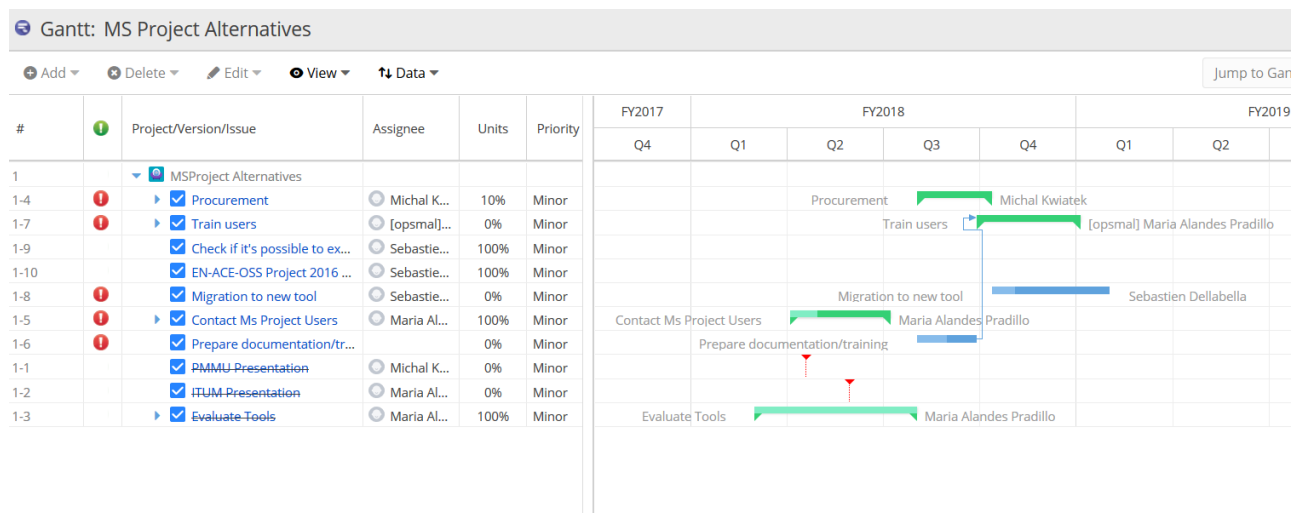

Figure 7. Example of a gantt chart defined with the JIRA WBS Gantt Chart Plugin

\subsection{DHTMLX and Gantt Chart Viewer}

Gantt Chart Viewer is one of MS Project alternatives designed for users who just need to view Gantt charts but not to create or modify them. It integrates well with CERNBox, a custom cloud storage solution at CERN [4]. Gantt Chart Viewer is a simple, lightweight JavaScript application developed at CERN. It relies on the open source DHTMLX 3rd party component, 
which provides libraries and two external services for importing and exporting different file formats [7].

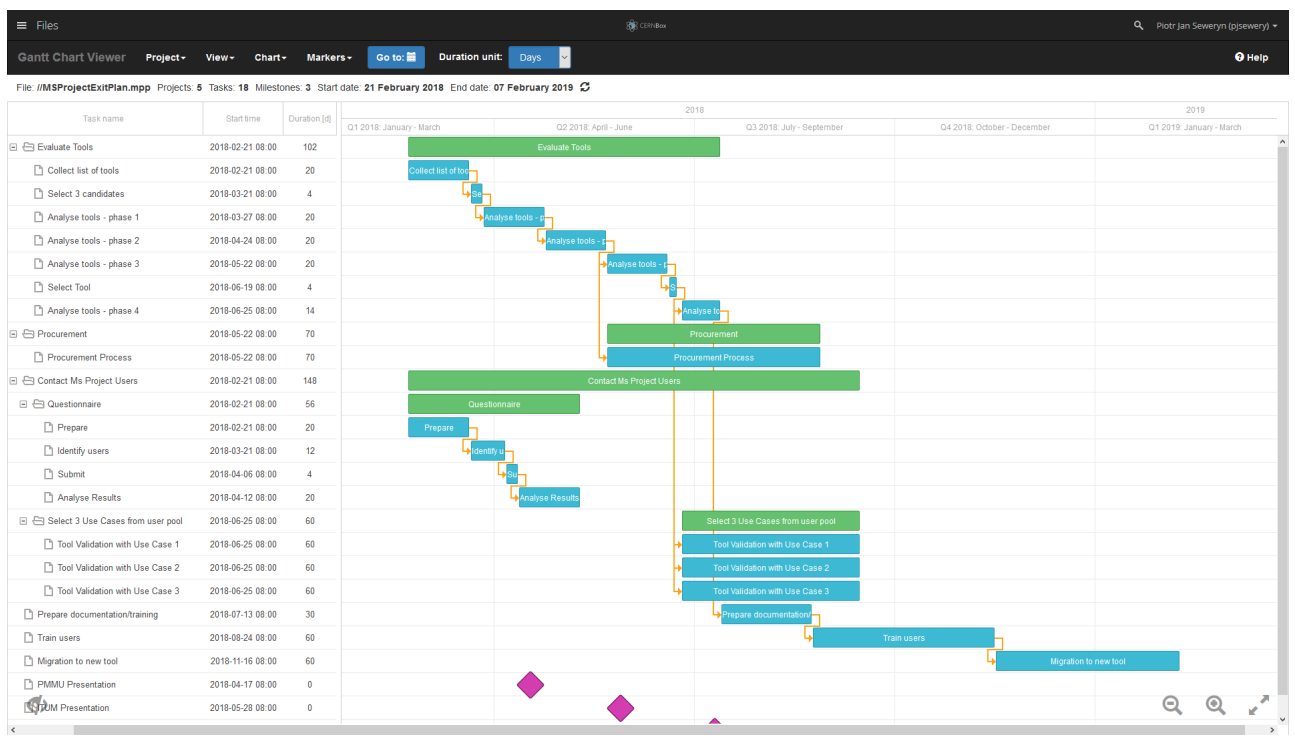

Figure 8. Gantt Chart Viewer application for CERNBox - User Interface

The Intuitive User Interface (UI), presented in the Figure 8, allows changing the chart's scale granularity (from hours to decades), adjusting display (themes, grid options, weekend highlights), adding markers and jumping between dates. On top of the integration with CERNBox, it is also possible to open files from a local hard drive. Finally, the chart's area has some built in controls to facilitate manipulation like iterative zoom in/out, full-screen mode, toggling a table's visibility and adjusting its size. In the context of the application, a help page with user manual and known issues/limitations list is also available.

Gantt Chart Viewer has been available in production since June 2019. New features and improvements have been added since then. Like JIRA Gantt Chart plugin, the maintenance and operations of this application is almost negligible and the effort to run it is well integrated in the existing applications provisioning team in the IT department. After the positive feedback received by the users, it is foreseen to extend the tool with extra features such as: enabling simple editing functionality (adding, removing, modifying tasks, saving files), adding tools for resources (i.e. team planner) and enhancing navigation in particular filtering, grouping and sorting table's contents. These improvements could imply a considerable reduction of further MS Project licences and they will be definitely taken into account in the longer term plans.

\section{User Strategy}

\subsection{Communication}

One of the challenges to introduce change at CERN is the fact that the user community is very heterogeneous. Some aspects of this diversity are listed below: 
- CERN has a large international and multicultural workforce. In particular, IT services are available to 40,000 potential users sitting all around the world. 15,000 users are on average physically on site every month.

- CERN has 16 different departments and units. Each of these has its own working culture.

- There are hundreds of projects, experiments and teams working at CERN and they all have different manpower and timing constraints to effectively incorporate change.

- The needs of all these user communities are very different. For this reason, sometimes the IT department has to propose several applications in the same domain to serve different purposes.

- The level of expertise also varies and since there is a high turn over, training and documentation are essential for newcomers.

- Finally, the desktop landscape is as diverse as their owners. Applications should be multi platform for at least Linux, Windows and Mac. Mobile platforms and other devices like tablets are sometimes needed, such as for users working on the experiments and accelerator complex for whom carrying light and portable devices is very convenient.

The communication strategy required several iterations to meet representatives from the most relevant user communities. This basically implied meeting or contacting people from all departments and the main experiments. This was done during 2018 in the form of face to face interviews when possible or via mail exchanges for those users who were not based at CERN. At CERN there is a very active project management community. This community meets regularly and organises lectures on project management related topics. Two lectures were organised in April 2018 [8] and July 2018 [9] to present the strategy and plans for MS Project Alternatives. This helped in spreading the strategy and reaching out to key users. During 2019, regular updates on the project were given at the user meetings coordinated by the IT Department.

\subsection{Training}

Getting started tutorials for JIRA Gantt Chart Plugin were prepared and delivered throughout the year by CERN IT members. 7 tutorials in total were attended by around 50 project leaders and team members in 2019.

As Gantt Chart Viewer was deployed only for read access, no tutorials were organised but a detailed documentation was prepared and published for the users.

\subsection{Migration}

Since the last quarter of 2018 , a closer collaboration was established with the team managing the accelerator complex schedules and with the team managing the ATLAS upgrade schedule. In both cases, due to the needs of the project, it was decided to migrate to MS Project 365 as a first step. This allowed these teams to move into a collaborative environment. It also meant making use of the new licence model based on individual licences, where it was possible to choose from MS Project Professional (write access) and Essentials (read access) licences. This licence model could better fit the needs of the different users. As a second step, the accelerator complex schedules were also made available for read access using DHTMLX technology, allowing to reduce even more the number of read licences. Smaller teams were invited to consider alternatives as of March 2019. In November 2019, a cleanup campaign was carried out removing all MS Project 2016 installations. At that moment, all users who needed MS Project had to request a named licence that would allow them to install and use 
MS Project 365 desktop version. After the cleanup campaign, the number of MS Project installations was reduced to half. Work is ongoing to better monitor the use of JIRA Gantt Chart plugin and Gantt Chart Viewer. At the time of the article publication, there are no reliable numbers on the use of the deployed alternative applications.

\section{Conclusions and Lessons Learnt}

Some of the conclusions and lessons learnt after evaluating and deploying MS Project Alternatives are summarised below:

- Although MS Project is still an application available to CERN users, if there is a justified need for it, the MS Project Alternatives project had successfully reduced the number of MS Project licences by the time the new Microsoft contract started in March 2019.

- In order to choose the most relevant alternative tools, it was critical to get to know the user communities and their needs. Considerable effort was dedicated to establishing links and to have a fruitful collaboration with them.

- The user survey contributed to have the necessary quantitative and qualitative data concerning the use of planning and scheduling tools. This was very helpful when evaluating alternative tools and for making estimations of future licensing needs.

- Alternative tools were evaluated and two applications were identified as the best candidates to fit the needs of most of the users: JIRA Gantt Chart and Gantt Chart Viewer based on DHTMLX.

- Criteria like web based deployment and the MS Project import feature were identified as essential to allow for collaboration and accessing legacy documents.

- Preparing documentation and training was an important stage of the project for which resources were planned and allocated. The tutorials were fundamental to help the users understand whether the alternative tools were appropriate for them and could be considered as an option.

- The cleanup campaign was an important milestone to push the users to consider migrating to the new tools or for requesting a MS Project licence.

- The experience gained with MS Project Alternatives will be very valuable for future similar MALT tasks such as the project for finding alternatives for MS Office.

\section{References}

[1] CERN Accelerator Coordination and Engineering Group, http://en.web.cern.ch/group/ace

[2] Peter Vankov, ATLAS Upgrade for the HL-LHC: meeting the challenges of a five-fold increase in collision rate, Hadron Collider Physics Symposium, 2011

[3] CERN Site Management and Buildings Department, https://smb-dep.web.cern.ch

[4] Hugo Gonzalez Labrador et al., Evolution of the CERNBox platform to support the MALT project, Proceedings of 24th International Conference on Computing in High Energy \& Nuclear Physics (CHEP 2019)

[5] JIRA Software, https://www.atlassian.com

[6] A. Gonzalez Alvarez et al., Extending software repository hosting to code review and testing, Proceedings of 21st International Conference on Computing in High Energy \& Nuclear Physics (CHEP 2015) 
[7] XB Software, https://dhtmlx.com/

[8] CERN Project Management Meet-up on April 2018, https://indico.cern.ch/event/683418/

[9] CERN Project Management Meet-up on July 2018, https://indico.cern.ch/event/741752/

[10] Gantt-Chart for JIRA by Frank Polscheit, https://marketplace.atlassian.com/apps/28997/ganttchart-for-jira?hosting=datacentertab $=$ overview

[11] MPXJ Library to manipulate project information, applwww.mpxj.org 